\title{
Prevalence of bipolar disorder in children and adolescents with attention-deficit hyperactivity disorder ${ }^{\dagger}$
}

\author{
Amani Hassan, Sharifah Shameem Agha, Kate Langley and Anita Thapar
}

\section{Background}

Some research suggests that children with attention-deficit hyperactivity disorder (ADHD) have a higher than expected risk of bipolar affective disorder. No study has examined the prevalence of bipolar disorder in a UK sample of children with ADHD.

\section{Aims \\ To examine the prevalence of bipolar disorder in children diagnosed with ADHD or hyperkinetic disorder.}

\section{Method}

Psychopathology symptoms and diagnoses of bipolar disorder were assessed in 200 young people with ADHD (170 male, 30 female; age 6-18 years, mean 11.15 , s.d. $=2.95$ ).
Rates of current bipolar disorder symptoms and diagnoses are reported. A family history of bipolar disorder in parents and siblings was also recorded.

\section{Results}

Only one child, a 9-year-old boy, met diagnostic criteria for both ICD-10 hypomania and DSM-IV bipolar disorder not otherwise specified.

\section{Conclusions}

In a UK sample of children with ADHD a current diagnosis of bipolar disorder was uncommon.

\section{Declaration of interest}

None.
There is increasing interest in the potential overlap between attention-deficit hyperactivity disorder (ADHD) and bipolar affective disorder. Some studies suggest that the two disorders commonly co-occur. ${ }^{1,2}$ Other researchers are more sceptical. ${ }^{3}$ Previous studies from the USA have shown rates of bipolar disorder in children with ADHD that vary widely - from less than $2 \%$ to $23 \%$. ${ }^{2,4}$ There is also divided opinion on how bipolar disorder is best defined. The aim of this study was to investigate the prevalence of bipolar disorder in a UK sample of children with ADHD.

\section{Method}

\section{Participants}

The sample consisted of the first 200 participants in a larger ongoing genetic study of ADHD. Participants were consecutively recruited from community child and adolescent psychiatry and paediatric out-patient clinics in South Wales and other parts of the UK. Each child had a clinical diagnosis of ADHD or was undergoing assessment for a diagnosis. No pre-selection strategy was used apart from the exclusion criteria listed below and the willingness of families to participate. Psychopathology was assessed using the Child and Adolescent Psychiatric Assessment (CAPA) research diagnostic interview, ${ }^{5}$ which was used to confirm that all participants met DSM-III-R or DSM-IV criteria for ADHD or ICD-10 criteria for hyperkinetic disorder. ${ }^{6-8}$ To meet study inclusion criteria the participant had to be living with at least one biological parent, be British, White and have a full-scale IQ of 70 or above, assessed using the Wechsler Intelligence Scale for Children version IV. ${ }^{9}$ Exclusion criteria comprised any major neurological or genetic condition such as epilepsy or fragile-X syndrome, psychosis (but not mood disorder), pervasive developmental disorder and Tourette syndrome (although those

†See pp. 171-172, this issue with other tic disorders were not excluded). Ethical approval for the study was obtained from the Wales Multicentre Research Ethics Committee and written informed consent and assent were obtained from participating parents and children.

\section{Assessments}

Interviews were conducted by trained and supervised graduate and postdoctoral psychologists. The 'parent' version of the CAPA, a reliable, well-established semi-structured research diagnostic interview that assesses current symptom presence, was used to assess clinical symptoms of ADHD, oppositional defiant disorder, conduct disorder, anxiety disorder and mood disorders, including bipolar disorder. The interview section on hypomania/mania covers mood changes (elation and irritability) that have a duration of at least $1 \mathrm{~h}$. If there is no mood change, criterion B hypomania/ mania items are not assessed. The child version of the CAPA includes the same questions as the parent interview, although it does not assess self-reported ADHD symptoms. ${ }^{10}$ This measure was additionally used to interview those aged 12 years and over. Comorbidities (including bipolar disorder) were considered present if reported by either parent or child. ${ }^{11}$ To assess the ICD-10 and DSM-IV criteria of ADHD pervasiveness in more than one setting, reports of symptoms in school were obtained using teacher reports on the Child ADHD Teacher Telephone Interview or the Conners Teacher Rating Scale. ${ }^{12,13}$

Symptoms and diagnoses according to DSM-IV and ICD-10 criteria were generated using information from the CAPA. All interviews were audiotaped, and interviewers were supervised weekly by an experienced clinician (A.T.). Reports of family psychiatric history were obtained for parents and biological siblings, by asking the parent about each parent and sibling in turn. The participating children had a total of 409 siblings; the number of siblings for each individual ranged from 0 to 6 (mean 2). Parents also completed questionnaires concerning demographic and family information. 


\section{Results}

The 200 participants, $170(85 \%)$ of whom were male and 30 $(15 \%)$ female, were aged $6-18$ years (mean 11.15 , s.d. $=2.95$; median 11.00 , s.d. $=2.95)$. The social class of 176 families $(24$ families had missing data) was determined by classifying the occupation of the main wage-earner in the family using the UK Standard Occupation Classification 2000 (www.ons.gov.uk). The families were then split into three social class categories: high social class $(12.5 \%, n=22)$, comprising families from professional and managerial jobs; medium social class $(36.4 \%, n=64)$, comprising those with skilled occupations (manual, non-manual) and partially skilled workers; and low social class $(51.1 \%, n=90)$, comprising those with unskilled jobs and unemployed or unclassified individuals.

\section{ADHD}

The mean number of ADHD symptoms (from a possible 18) was 15.97 (s.d. =1.98). All participants met criteria for at least one of the following: a DSM-III-R diagnosis of ADHD (99.0\%), an ICD-10 diagnosis of hyperkinetic disorder (27.5\% hyperkinetic disorder, $34.5 \%$ hyperkinetic conduct disorder) or a DSM-IV diagnosis of ADHD (78.0\% ADHD combined type, 10.5\% hyperactive/impulsive type, $6.5 \%$ inattentive type).

\section{Comorbidities}

Oppositional defiant disorder according to DSM-IV criteria was diagnosed in $42.0 \%$ of the sample and conduct disorder in $14.5 \%$. Four participants $(2.0 \%)$ received a diagnosis of generalised anxiety disorder. One $(0.5 \%)$ participant had social anxiety disorder and $2(1.0 \%)$ met criteria for separation anxiety disorder. Three children (1.5\%) met criteria for major depressive episode. Twenty $(10.0 \%)$ had a tic disorder. The comorbidity rates of oppositional defiant and conduct disorders were similar to those found in other European ADHD studies, ${ }^{14,15}$ but rates of anxiety and depression were lower than in some US clinic-based studies. ${ }^{16}$

\section{Bipolar disorder}

When both DSM-IV and ICD-10 research diagnostic criteria were applied, only one child, a 9-year-old boy, met ICD-10 criteria for hypomania and DSM-IV criteria for bipolar disorder not otherwise specified (NOS). He had expansive mood (a criterion A symptom) that lasted for 2 weeks and three criterion B symptoms (talkativeness, decreased need for sleep and distractibility during the mood disturbance) needed to diagnose an episode of hypomania and bipolar disorder. The CAPA requires that the criterion B symptoms represent a change from usual (i.e. it does not allow simply double-coding of ADHD items). For confirmation of the diagnoses, three clinicians (one masked to the possible diagnosis) reviewed the audiotaped interview. All gave a clinical diagnosis of bipolar disorder NOS, because hypomanic episodes (not mania) with no depressive episode were reported. The child had a family psychiatric history of mood disorder, as his mother had bipolar disorder. No mental health problem was reported for the father. The affected child met DSM-IV criteria for combined type ADHD and ICD-10 criteria for hyperkinetic conduct disorder. There was no case of rapid cycling.

\section{Mania and hypomania symptoms}

Symptoms of mania and hypomania, including mood disturbance of less than 4 days, were found in only one child, who met criteria
Table 1 Distribution of DSM-IV and ICD-10 symptoms of mania and hypomania $(n=200)$

Symptom $n(\%)$

Expansive mood $1(0.5)$

Irritable mood

More talkative $^{\text {a }}$

$1(0.5)$

Flight of ideas ${ }^{a}$ $0(0.0)$

Pressure of speecha

$0(0.0)$

Increased goal-directed activity (motor pressure) $^{\mathrm{a}} \quad 0(0.0)$

Psychomotor agitation ${ }^{\text {a }}$

$0(0.0)$

Decreased need for sleep ${ }^{a}$

$1(0.5)$

Distractibility ${ }^{a}$

Grandiosity ${ }^{\mathrm{a}}$

$1(0.5)$

$0(0.0)$

Reckless behaviour ${ }^{\mathrm{a}}$

$0(0)$

Increase in adaptive activity ${ }^{a}$

a. Symptom presence rated if there is mood disturbance lasting $\geqslant 1 \mathrm{~h}$, not necessarily occurring exclusively during the mood episode.

for bipolar disorder, and in 19 individuals who reported persistent irritability (Table 1).

\section{Family history of bipolar disorder}

A family history of bipolar disorder was absent in fathers and siblings, but was reported by three mothers (Table 2).

\section{Discussion}

This study is, to our knowledge, the first to examine the current prevalence of bipolar affective disorder and hypomania/mania symptoms in a UK sample of children and adolescents with a diagnosis of ADHD. In this study the prevalence of bipolar disorder or hypomania was low $(0.5 \%$ of the sample). A recent epidemiological study of 5326 UK children aged 8-19 years that used a different diagnostic interview, the Development and Well-Being Assessment, found that only $0.1 \%$ met DSM-IV criteria for bipolar disorder. ${ }^{17} \mathrm{~A}$ similar rate of bipolar disorder $(0.1 \%)$ was reported from the USA in the Great Smoky Mountains epidemiological study of children aged 9-13 years, which used the CAPA. ${ }^{18}$ Thus our estimate suggests that there is no greatly elevated level of unidentified bipolar disorder in children with ADHD who are currently referred to district child psychiatry and paediatric out-patient settings. The overall rate of a family history of bipolar disorder was also within population prevalence estimates of this disorder $\left(0.5-1.5 \%\right.$ in adults). ${ }^{19}$

Our low rates of bipolar disorder differ substantially from some studies in the USA, although reported rates vary widely. These studies have been reviewed extensively elsewhere. ${ }^{20}$ There are a number of possible reasons for this variation, including

Table 2 Reported psychiatric history in parents and siblings

\begin{tabular}{|c|c|c|c|}
\hline Diagnosis $^{a}$ & $\begin{array}{l}\text { Mothers } \\
n=200 \\
n(\%)^{b}\end{array}$ & $\begin{array}{l}\text { Fathers } \\
n=200 \\
n(\%)^{b}\end{array}$ & $\begin{array}{l}\text { Siblings } \\
n=409 \\
n(\%)^{b}\end{array}$ \\
\hline ADHD & $2(1.0)$ & $5(2.5)$ & $46(11.2)$ \\
\hline Depression & 49 (24.5) & $18(9.0)$ & $2(0.5)$ \\
\hline Bipolar disorder & $3(1.5)$ & $0(0.0)$ & $0(0.0)$ \\
\hline Schizophrenia & $1(0.5)$ & $1(0.5)$ & $1(0.2)$ \\
\hline \multicolumn{4}{|c|}{$\begin{array}{l}\text { ADHD, attention-deficit hyperactivity disorder. } \\
\text { a. Diagnoses are not mutually exclusive as many participants had more than one } \\
\text { diagnosis. } \\
\text { b. Percentage of whole sample. }\end{array}$} \\
\hline
\end{tabular}


sample selection (specialist clinic $v$. routine out-patient services), the age group studied, whether or not researchers started with index cases of bipolar disorder or ADHD, and differences in diagnostic practice. Our sample consisted of routine cases from child and adolescent out-patient psychiatry and paediatric services rather than specialist clinics, so we might expect lower rates of bipolar disorder than in studies of samples from specialist centres. ${ }^{2}$ The variation in ascertainment across different studies is likely to have contributed to the varying prevalence rates of bipolar disorder in ADHD. Another possibility is that our sample had not yet passed through the age of risk (the median age in our sample was 11 years). For example, Biederman et al found a slightly higher rate of bipolar disorder over time in a cohort of 140 boys with ADHD after 4 years $-11 \%$ at baseline (mean age 10.7 years) and an additional $12 \%$ of new cases at follow-up (mean age 14.6 years). ${ }^{2}$ We have to consider that the Biederman study was a longitudinal study and ours was cross-sectional, although the baseline prevalence rate in the former sample was still much higher than that found in our UK sample.

One key issue is that the reported relationship between ADHD and bipolar disorder also appears to vary depending on the diagnosis of the index cases. Thus, in general, rates of ADHD in those with bipolar disorder (especially early-onset disorder) appear to be much higher than rates of bipolar disorder in those with ADHD. ${ }^{21,22}$ There is reasonably consistent evidence suggesting high rates of ADHD in samples of bipolar disorder. The Course and Outcome of Bipolar Illness in Youth study, a cohort study involving children and adolescents with bipolarspectrum disorders, found the rate of ADHD to be $58.6 \% .^{22}$ Another study showed an increased rate of ADHD in youths with bipolar disorder (32\%) compared with adults with bipolar disorder $(3 \%){ }^{23}$ One possibility is that there is a subgroup of individuals with early-onset bipolar disorder accompanied by comorbid ADHD. Alternatively, ADHD could be a herald of later bipolar disorder in a subgroup of genetically susceptible individuals, indexed by a strong family history of bipolar disorder. However, the evidence to date suggests that the majority of individuals with ADHD do not develop bipolar disorder or show a relationship with bipolar disorder, given that family studies of ADHD do not seem to show elevated rates of bipolar disorder in relatives. ${ }^{24}$

Another issue is variation in diagnostic practice. A recent study into the age at onset of bipolar disorder in the USA and Europe (in children without ADHD) showed that the rate of childhood-onset bipolar disorder in the USA is double that in Europe. ${ }^{25}$ An investigation of national trends in the USA has also shown a recent rapid increase in the rate of diagnosis of bipolar disorder. ${ }^{23}$ This has raised the possibility that child psychiatrists in the UK are missing bipolar disorder. An alternative explanation is that there are transatlantic differences in diagnosing bipolar disorder and one study does indeed suggest that UK clinicians interpret hypomania symptoms in children differently from their US counterparts. ${ }^{26}$ However, our study suggests that when a standardised research diagnostic interview and ICD-10 or DSM-IV criteria for bipolar disorder are used in the UK, the rate of bipolar disorder in out-patients with ADHD is low. Rates of bipolar disorder in the USA that have also been based on standardised interviews and diagnostic criteria have varied widely. ${ }^{2,20}$ It is not known whether the exact type of diagnostic instrument used is important because many current diagnostic instruments, including the CAPA, have yet to be evaluated or compared with regard to sensitivity and specificity specifically for detecting bipolar disorder. Another possibility is that referral patterns for ADHD vary in different countries. For example, rates of comorbid depression and ADHD inattentive type appear to be lower in our sample and in a UK community study (Ford et $a l^{27}$ ) than in US studies (e.g. that by Elia et al. ${ }^{16}$ ) Many studies of bipolar disorder have not reported the rates of ADHD subtypes, and this needs to be considered in the future because it is possible that the relationship between ADHD and bipolar disorder varies for the different $\mathrm{ADHD}$ subtypes. A final explanation of the observed variation in prevalence rates of bipolar disorder is that there is genuine geographical variation for unknown reasons.

\section{Abnormal irritable mood}

Some researchers put much emphasis on the importance of irritability when diagnosing bipolar disorder in children and adolescents, arguing that the presentation and course are different from adult bipolar disorder. ${ }^{28}$ Most clinicians and researchers suggest that irritability needs to be episodic in nature. However, other researchers have suggested that it is the severity of irritability that distinguishes bipolar disorder, rather than its episodic nature. $^{29}$ Although in our sample 19 individuals reported persistent irritable mood none met the level of severity required by Mick et $a l^{29}$ and similarly none of these children had any criterion B symptom, although given that many of these symptoms (e.g. distractibility, increased activity, talkativeness) are almost inevitably present in ADHD, we only included these symptoms if they were reported as increased during the episodes of the irritable mood (i.e. episodic). Other investigators have suggested that these overlapping symptoms are not of diagnostic importance as they failed to differentiate between ADHD and bipolar disorder in one study, and suggest that elated mood and grandiosity are of greater diagnostic importance to bipolar disorder than is irritability, as they found the latter to be a shared symptom of ADHD and bipolar disorder, and of higher prevalence in people with ADHD but no mood disorder. ${ }^{30}$

\section{Limitations}

Like all studies, ours has limitations that must be considered, including ascertainment issues. First, excluding cases with psychosis would have an impact on the prevalence of bipolar disorder in our sample, as mania may present with psychotic symptoms. However, the contentious research and clinical issue at present is not to do with psychosis that is likely to be picked up but rather with the overlap of bipolar disorder and ADHD. We also cannot rule out the possibility that clinicians pre-selected ADHD cases without mood disturbance, although this was not an exclusion criterion and informal enquiry suggested that this approach had not been adopted by clinics. Another limitation is that the CAPA assesses current symptoms. Also, some have suggested that as most child and adolescent research diagnostic interviews are based on stringent interpretations of DSM and ICD criteria, current instruments might underdetect bipolar disorder. ${ }^{31}$ As all participants were White, we cannot generalise our findings to other ethnic groups; our sample size was relatively small, and participants might not have been old enough for us to detect increased rates of bipolar disorder. However, the sample ages are representative of current UK child and adolescent mental health service attenders with ADHD. Our findings might have been different in older adolescents and young adults. In line with other ADHD studies our sample was predominately male (85\%), so further investigations might be needed to generalise to the female population. Finally, the family psychiatric history was reported by family members and not formally obtained from medical notes or by direct interview with each family member, and reported rates of disorder may therefore be lower than the true estimate. 
In conclusion, in a UK sample of children with ADHD, current bipolar affective disorder and bipolar symptoms were uncommon.

Amani Hassan, MRCPsych, Sharifah Shameem Agha, MSC, Child and Adolescent Mental Health Services Network, Cwm Taf Health Board, and Medical Research Council (MRC) Centre for Neuropsychiatric Genetics, Department of Psychological Medicine and Neurology, Cardiff University; Kate Langley, PhD, Anita Thapar FRCPsych, MRC Centre for Neuropsychiatric Genetics, Department of Psychological Medicine and Neurology, Cardiff University, Cardiff, UK

Correspondence: Professor Anita Thapar, MRC Centre for Neuropsychiatric Genetics, Department of Psychological Medicine and Neurology, 4th Floor Main Building, Heath Park, Cardiff CF14 4XN, UK. E-mail: thapar@cardiff.ac.uk

First received 11 Feb 2010, final revision 1 Nov 2010, accepted 3 Nov 2010

\section{Funding}

The study was supported by a grant from the Wellcome Trust on the genetics of attention deficit hyperactivity disorder to A.T., M. O'Donovan, M. Owen, P. Holmans, M.B.M. van den Bree (Cardiff University) and L. Kent (St Andrew's University).

\section{Acknowledgements}

The authors thank the families who contributed their time to the study, the participatin National Health Service clinicians and the research assessment team from Cardiff University, Department of Psychological Medicine and Neurology, for their assistance and support with the research. Dr Rhys Bevan Jones assisted by independently reviewing audiotaped interviews for clinical consensus.

\section{References}

1 Butler SF, Arredondo DE, McCloskey V. Affective comorbidity in children and adolescents with attention deficit hyperactivity disorder. Ann Clin Psychiatry 1995; 7: 51-5.

2 Biederman J, Faraone S, Mick E, Wozniak J, Chen L, Ouellette C, et al. Attention-deficit hyperactivity disorder and juvenile mania: an overlooked comorbidity? J Am Acad Child Adolesc Psychiatry 1996; 35: 997-1008.

3 Kent L, Craddock $\mathrm{N}$. Is there a relationship between attention deficit hyperactivity disorder and bipolar disorder? J Affect Disord 2003; 73: 211-21.

4 McGough JJ, Loo SK, McCracken JT, Dang J, Clark S, Nelson SF, et al. CBCL Pediatric Bipolar Disorder Profile and ADHD: comorbidity and quantitative trait loci analysis. J Am Acad Child Adolesc Psychiatry 2008; 47: 1151-7.

5 Angold A, Costello EJ. The Child and Adolescent Psychiatric Assessment (CAPA). J Am Acad Child Adolesc Psychiatry 2000; 39: 39-48.

6 American Psychiatric Association. Diagnostic and Statistical Manual of Mental Disorders (3rd edn, revised) (DSM-III-R). APA, 1987.

7 American Psychiatric Association. Diagnostic and Statistical Manual of Mental Disorders (4th edn, Text Revision) (DSM-IV-TR). APA, 2000.

8 World Health Organization. The ICD-10 Classification of Mental and Behavioural Disorders. WHO, 1993.

9 Weschler D. Weschler Intelligence Scale for Children - Fourth Edition (WISC-IV) Administration and Scoring Manual. Psychological Association, 2003.

10 Angold A, Costello EJ. A test-retest reliability study of child-reported psychiatric symptoms and diagnoses using the Child and Adolescent Psychiatric Assessment (CAPA-C). Psychol Med 1995; 25: 755-62.

11 Rutter M, Giller H, Hagell A. Antisocial Behavior by Young People. Cambridge University Press, 1998
12 Holmes J, Lawson D, Langley K, Fitzpatrick H, Trumper A, Pay H, et al. The Child Attention-Deficit Hyperactivity Disorder Teacher Telephone Interview (CHATTI): reliability and validity. Br J PSychiatry 2004; 184: 74-8.

13 Conners CK. A teacher rating scale for use in drug studies with children. Am J Psychiatry 1969; 126: 884-8.

14 Gillberg C, Gillberg IC, Rasmussen P, Kadesjo B, Soderstrom H, Rastam M, et al. Co-existing disorders in ADHD - implications for diagnosis and intervention. Eur Child Adolesc Psychiatry 2004; 13 (suppl 1): 180-92.

15 Asherson P, Brookes K, Franke B, Chen W, Gill M, Ebstein RP, et al. Confirmation that a specific haplotype of the dopamine transporter gene is associated with combined-type ADHD. Am J Psychiatry 2007; 164: 674-7.

16 Elia J, Ambrosini P, Berrettini W. ADHD characteristics: I. Concurrent comorbidity patterns in children and adolescents. Child Adolesc Psychiatry Ment Health 2008; 2: 15 .

17 Stringaris A, Santosh P, Leibenluft E, Goodman R. Youth meeting symptom and impairment criteria for mania-like episodes lasting less than four days: an epidemiological enquiry. J Child Psychol Psychiatry 2010; 51: 31-8.

18 Costello EJ, Angold A, Burns BJ, Stangl DK, Tweed DL, Erkanli A, et al. The Great Smoky Mountains Study of Youth. Goals, design, methods, and the prevalence of DSM-III-R disorders. Arch Gen Psychiatry 1996; 53: 1129-36.

19 Craddock N, Jones I. Genetics of bipolar disorder. J Med Genet 1999; 36 585-94.

20 Leibenluft E, Rich BA. Pediatric bipolar disorder. Annu Rev Clin Psychol 2008; 4: $163-87$.

21 Wozniak J, Biederman J, Kiely K, Ablon JS, Faraone SV, Mundy E, et al. Mania-like symptoms suggestive of childhood-onset bipolar disorder in clinically referred children. J Am Acad Child Adolesc Psychiatry 1995; 34 867-76.

22 Birmaher B, Axelson D, Strober M, Gill MK, Valeri S, Chiappetta L, et al. Clinical course of children and adolescents with bipolar spectrum disorders. Arch Gen Psychiatry 2006; 63: 175-83.

23 Moreno $C$, Laje $G$, Blanco $C$, Jiang $H$, Schmidt AB, Olfson $M$. National trends in the outpatient diagnosis and treatment of bipolar disorder in youth. Arch Gen Psychiatry 2007; 64: 1032-9.

24 Wozniak J, Biederman J, Mundy E, Mennin D, Faraone SV. A pilot family study of childhood-onset mania. J Am Acad Child Adolesc Psychiatry 1995; 34: 1577-83.

25 Post RM, Luckenbaugh DA, Leverich GS, Altshuler LL, Frye MA, Suppes T, et al. Incidence of childhood-onset bipolar illness in the USA and Europe. Br J Psychiatry 2008; 192: 150-1.

26 Dubicka B, Carlson GA, Vail A, Harrington R. Prepubertal mania: diagnostic differences between US and UK clinicians. Eur Child Adolesc Psychiatry 2008; 17: 153-61.

27 Ford T, Goodman R, Meltzer $\mathrm{H}$. The British Child and Adolescent Mental Health Survey 1999: the prevalence of DSM-IV disorders. J Am Acad Child Adolesc Psychiatry 2003; 42: 1203-11.

28 Leibenluft E, Charney DS, Towbin KE, Bhangoo RK, Pine DS. Defining clinical phenotypes of juvenile mania. Am J Psychiatry 2003; 160: 430-7.

29 Mick E, Spencer T, Wozniak J, Biederman J. Heterogeneity of irritability in attention-deficit/hyperactivity disorder subjects with and without mood disorders. Biol Psychiatry 2005; 58: 576-82.

30 Geller B, Zimerman B, Williams M, Delbello MP, Bolhofner K, Craney JL, et al. DSM-IV mania symptoms in a prepubertal and early adolescent bipolar disorder phenotype compared to attention-deficit hyperactive and normal controls. J Child Adolesc Psychopharmacol 2002; 12: 11-25.

31 Fisher $\mathrm{P}$, Galanter $\mathrm{C}$. A review of diagnostic instruments for pediatric bipolar disorder. Scientific Proceedings of the 55th Annual Meeting of the American Academy of Child and Adolescent Psychiatry. American Academy of Child and Adolescent Psychiatry, 2008. 